\title{
Factors Associated to Return to Sport after Surgical Repair of Achilles Tendon Ruptures. A Clinical and Functional Retrospective Study
}

\author{
R. Tanaka', T. Imaya ${ }^{1}$, S. Katsuki ${ }^{1}$, T. Sanada ${ }^{2}$, A. Fukai ${ }^{2,3}$, E. Honda ${ }^{2}$, H. Yoshitomi ${ }^{2}$ \\ 1 Central Department of Rehabilitation Medicine, Kanto Rosai Hospital, Kawasaki, Japan \\ 2 Sports Orthopedics Surgery, Kanto Rosai Hospital, Kawasaki, Japan \\ 3 Faculty of Medical Technology, Teikyo University, Kanto Rosai Hospital, Kawasaki, Japan
}

\section{CORRESPONDING AUTHOR:}

Ryuta Tanaka

Central Department of Rehabilitation

Medicine

Kanto Rosai Hospital

1-1 Kizuki Sumiyoshi-cho

Nakahara-Ku

211-8510 Kawasaki, Japan

E-mail: ryuta-tanaka@kantoh.johas.go.jp

DOI:

10.32098/mltj.03.2021.24

LEVEL OF EVIDENCE: 2B

\begin{abstract}
SUMMARY
Background. The factors that influence a successful return sport following Achilles tendon rupture repair have not been identified. Furthermore, the extent of heel-rise height index (HRHI) and Achilles tendon resting angle (ATRA) as indicators of Achilles tendon function recovery are unclear.

Methods. We included 94 subjects who underwent a first unilateral Achilles tendon repair between 2017 and 2019, and returned to sports 9 months after surgery. Preoperative activity was set at 100 points, and subjects were classified into two groups with $\geq 80$ points and $<80$ points. Multiple logistic regression analysis was performed. The cutoff value of the extracted factors was also calculated. Dependent variables were patient background, extent of heel-rise height index (HRHI), and Achilles tendon resting angle (ATRA) for the unaffected side.

Results. HRHI was only extracted as an influencing factor (odds ratio, 1.104)., with a cutoff value of $89.5 \%$. The ATRA required for this HRHI was $72.4 \%$ as the cutoff value calculated.

Conclusions. After Achilles tendon repair, the HRHI required for good sports activity. The HRHI was about $90 \%$, ATRA required was $70 \%$ or more. It is necessary to prevent Achilles tendon elongation after surgery.
\end{abstract}

\section{KEY WORDS}

Achilles tendon rupture repair; return to sports; Achilles tendon resting angle (ATRA); beel-rise height index (HRHI); rehabilitation; surgery; sports level classification.

\section{INTRODUCTION}

Various factors are involved in the recovery of function after an Achilles tendon rupture repair, and various evaluation tools have been used to assess the recovery. Factors that affect functional recovery after an Achilles tendon rupture repair include age, body mass index (BMI), and surgery $(1,2)$. The single-leg heel rise (HR) we incorporated into our functional evaluation is considered an important index for functional evaluation following surgery (3-5). We previous reported a correlation between achieving a single-leg $\mathrm{HR}$ and jogging and between performing 25 consecutive single-leg HR (continuous HR) and being able to return to sport (5). Studies have also reported that single-leg HR is an indispensable factor in returning to competition $(4,5)$. In contrast, regarding the elevation-unaffected ratio of the single-leg HR, a residual dysfunction in the heel-rise height index (HRHI) has been reported after Achilles tendon rupture repair $(6,7)$. Moreover, it is unclear how HRHI affects sports activities (8). Another factor to consider is the elongation of the Achilles tendon (6, 9, 10). A useful method for assessing tendon elongation is measuring the Achilles tendon resting angle (ATRA), which is reported to reflect the length of the tendon (11). ATRA was reported to demonstrate a positive correlation with the HRHI (12). 
Because minimized strength of the triceps surae is considered important, setting the angle of the tendon during surgery while suturing is essential, and also important when considering how to proceed with rehabilitation (13-15). However, it is unclear whether the ATRA meets the HRHI requirements for sports activities.

This study considered HRHI as one of the functional factors required for sports activities. It is important to demonstrate that ATRA is able to achieve the HRHI necessary for sporting activities. By doing so, it becomes possible to provide clear indicators of rehabilitation. Therefore, this study aimed to clearly define the HRHI and ATRA necessary for sports activities.

\section{METHODS}

This is a retrospective study. We extracted the necessary factors between the two groups and calculated the necessary cutoff value. All patients agreed to be included in research and ethics services. The study was approved by the Research Ethics Committee of our hospital (approval number: 202010). Research meets ethics Journal criteria (16).

\section{Subjects}

In this study, return to sports was defined as being able to participate in regular sports, matches, or match-style practice after undergoing surgery. The target populations were individuals who regularly engage in sports activities. In the past, when it comes to returning to sports, there is a wide range of topics, from interviewing patients, using sports participation scores, to objective sports performance indicators (17-20). However, much of the research is vague, "returning to preoperative sports levels $(21,22)$ ". It examines "quality and content when returning". The definition of returning to sports needs to be clear and straightforward. Therefore, the definition of sports return used to include participants in this study is defined as "participating in a match or participating in a match-style practice." Subjects excluded from this study were included in the "Level 0" category of sports level criteria (table I).

Table I. Sports level classification.

\begin{tabular}{l}
\hline Level 0 (L0): non-sports \\
\hline Level 1 (L1): recreation level \\
\hline Level 2 (L2): district convention, municipality level \\
\hline Level 3 (L3): prefectural level \\
\hline Level 4 (L4): national level \\
\hline Level 5 (L5): professional, olympic level \\
In the present study level 0 is excluded.
\end{tabular}

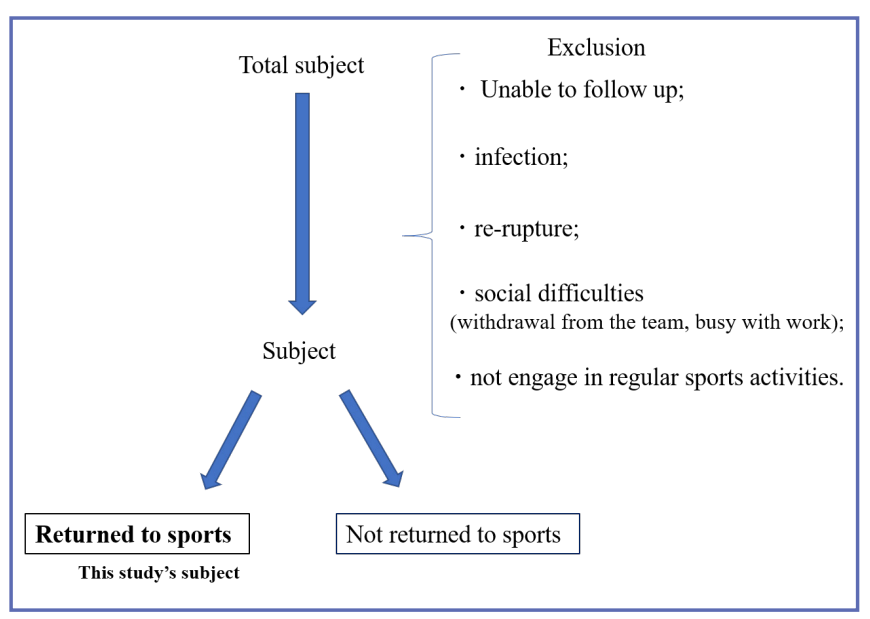

Figure 1. Patient rectuitment flow chart.

From January 2017 to August 2019, 342 subjects underwent unilateral Achilles tendon rupture repair in our center within 3 weeks of injury. Of these, the 94 subjects who were able to participate in the 9-month follow-up and return to sports were included in this study (figure 1), which used a retrospective questionnaire.

\section{Surgery}

The half-mini-Bunnell method (Uchiyama method), where the nodule is sutured to the stump (4), was used in all cases. The knee joint was in the $90^{\circ}$ flexion position, and the ankle plantar flexion angle on the unaffected side was adjusted further by $5^{\circ}$. A repair was sandwiched between the bundles, each sutured distally and proximally with the same degree of tension. The surgery is performed by 6 doctors belonging to our hospital, each with more than 10 years of experience as an orthopedic surgeon.

\section{Rehabilitation}

On postoperative day 5 , the below-knee cast was changed to a walking cast and used for 2 weeks. Patients were discharged after receiving instructions on all possible full weight-bearing gaits. The range of motion and active movement were expanded with a focus on the removal of adhesions around the wound. HR in the sitting position was performed on week 3 after repair, and double-leg HR in the standing position was performed from week 5 to 6 after surgery. Subjects started with single-leg HRs from weeks 8 to 9 after surgery. The angle setting of the orthosis was gradually changed from $-20^{\circ}$ to $-10^{\circ}, 0^{\circ}$, and $10^{\circ}$ according to the acquired angle. The brace was removed at week 10 after the 
operation. If $>50 \%$ of the HRHI was possible, the subject was allowed to start jogging, and after acquiring continuous HR, the subject shifted to practicing sports activities such as jumping or stepping actions (jumping movement). We proceeded with rehabilitation with the target of returning to sports in 5 months $(4,5)$.

\section{Outcome measurement}

\section{ATRA}

The ATRA was measured in the prone position, with the knee joint in the $90^{\circ}$ flexion position, with the ankle joint fully relaxed, and the ankle joint natural plantar flexion angle. The angle between the fibula head and the fifth metatarsal was measured in $1^{\circ}$ increments using a standard 30 $\mathrm{cm}$ long arm goniometer (figure 2 ). The evaluation determined the ratio with the unaffected side.

\section{HRHI}

HR was performed on a single leg while the subject was standing, with the knees in the extended position and the upper limbs supporting the wall to the extent that the fingers were balanced. When the heel was raised, the distance of the heel bottom from the floor was measured with a standard tape. Measurement is performed in $0.5 \mathrm{~cm}$ units in consideration of measurement error, the ratio between the affected and unaffected sides was calculated (figure 3).



Figure 2. Achires tendon resting angle (ATRA) inspection and measurement method.

The angle between the fibula head and the fifth metatarsal bone is measured with an angle meter, and the ratio between the effected side and unaffected side is calculated.

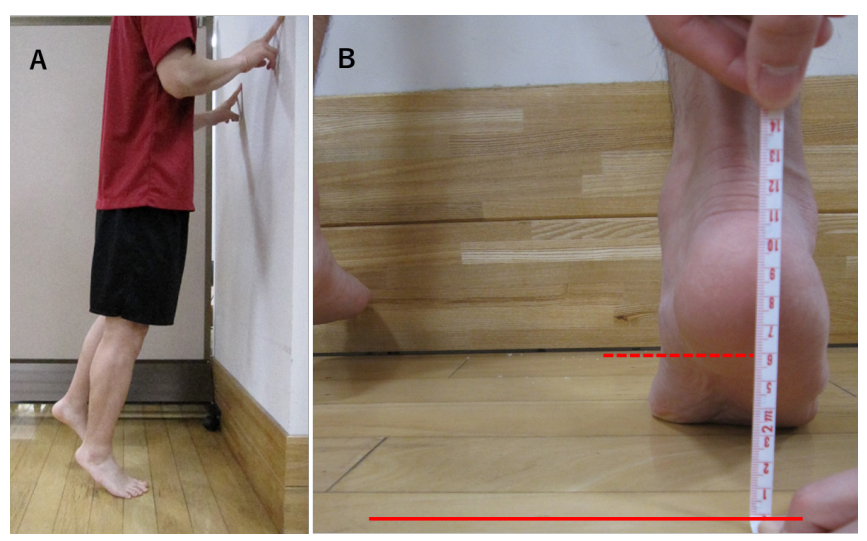

Figure 3. Heel rise height index (HRHI) inspection and measurement method.

(A) The upper limbs are balanced by putting fingers on the wall.Knees should be in the extended position. (B) Measure the bottom of the calcaneus from the floor and compare the laterality.

\section{Study protocol and statistical analysis}

At 9 months after surgery and return to sports, patients were asked for a subjective recovery score. As a result, the average was $80.2 \pm 13.2$ points. The subjects were divided into two groups, which were used as dependent variables. Those with a subjective recovery score of $\geq 80$ points were classified in the good group $(\mathrm{N}=68$, average recovery rate, 86.9 \pm 6.4 points), and those with a subjective recovery score of $<$ 80 points were classified in the poor group $(\mathrm{N}=26$, average recovery rate, $62.7 \pm 13.1$ points).

\section{Patient demographics}

Between the two groups, Waiting period, Age, Sports Level, BMI, ATRA, HRHI, The Pain rate, and The items of The Anxiety rate were compared (figure $4 \mathrm{~A}$ ).

\section{Movement starting time and achieved time}

Between the two groups, Full Dorsal flexion ROM achieved, Jogging start, HRHI 50\% achieved, Continuous HR achieved, Jumping Movement achieved (Perform 5 consecutive single-legged jumps on the spot), and Return to sports achieved were compared at movement starting time and achieved time (figure $4 \mathrm{~B}$ ).

Regarding the items of Patient demographic and Movement starting time and achieved time, the differences between the two groups were compared. The presence or absence of a normal distribution was evaluated. Variables that were normally distributed were analyzed using an unpaired t-test, and variables that were not normally distributed were evaluated using the Mann-Whitney $\mathrm{U}$ test. Pain and anxiety rates were compared using the chi-square test. 


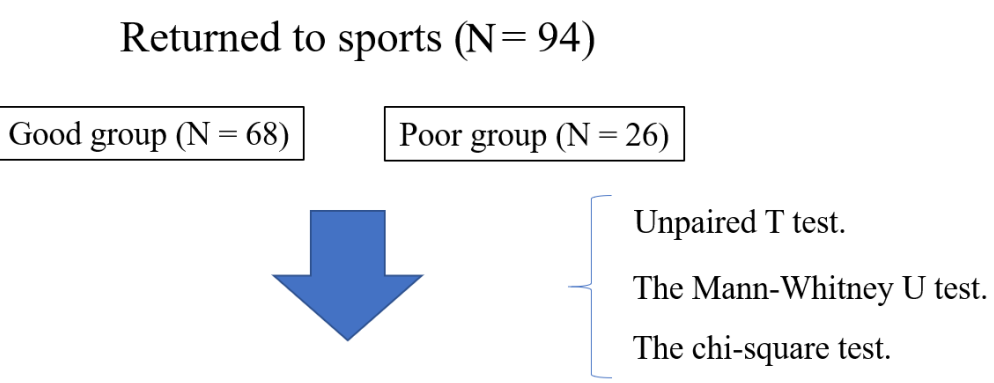

A: Patient demographic

Waiting period, Age, Sports Level, BMI, ATRA, HRHI, The Pain rate, The Anxiety rate.

\section{B: Movement starting time and achieved time}

Full Dorsal flexion ROM achieved, Jogging start, HRHI 50\% achieved, ContinReturn to sports achieved, Continuous HR achieved, Jumping Movement achieved, Return to sports achieved.

Figure 4. Study protocol flow chart (A) Patient demographic. (B) Movement starting time and achieved time.

\section{Outcomes of interest}

Age, sports level, BMI, ATRA, HRHI, pain rate, and anxiety rate were assessed (figure 5) and used as target variables for the multiple logistic regression analysis. We defined the good group as 1 and the poor group as 0 , and these groups were the dependent variables. Then, each evaluation item was set as an independent variable, and the test was performed taking into consideration the problem of multicollinearity between the variables.

The cutoff value was calculated using the receiver operating characteristic (ROC) curve of the extracted factors. In addition, the positive and negative predictive values were calculated based on the cutoff value.

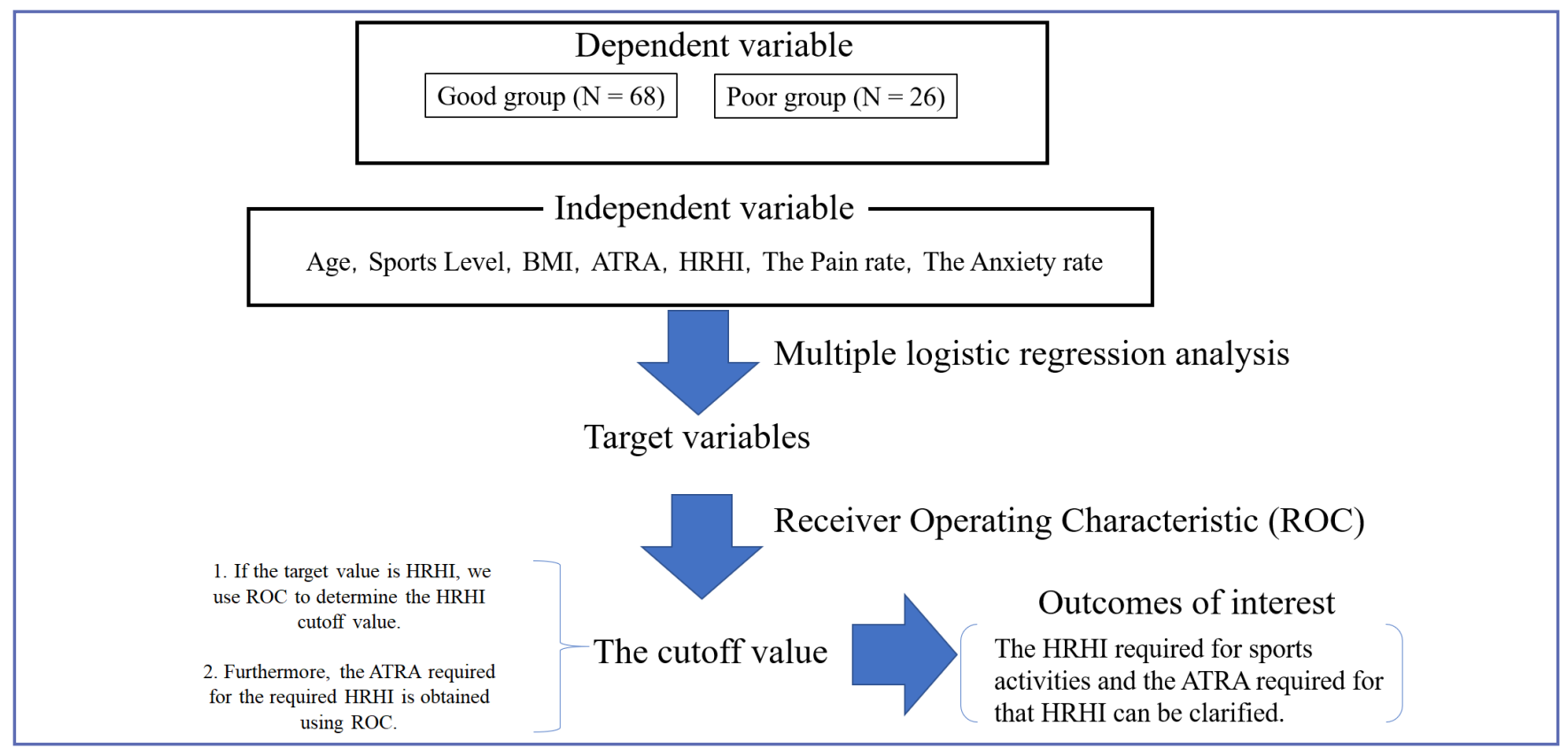

Figure 5. Study protocol flow chart (outcomes of interest). 
When the HRHI was included in the factors extracted, the obtained points were classified into two groups: the first group satisfied the cutoff value of HRHI and the other group did not. The ATRA required for that HRHI was determined from the ROC curve.

For all the data analysis, SPSS version 25.0 for Windows (IBM Corp., Armonk, NY, USA) was used, and the significance level was set at $<5 \%$.

\section{RESULTS}

\section{Patient recruitment}

Of the 342 patients who underwent surgery, those who were unable to follow up for 9 months $(\mathrm{N}=127)$, were infected $(\mathrm{N}=12)$, experienced a re-rupture $(\mathrm{N}=5)$, did not engage in regular sports activities $(\mathrm{N}=40)$, or did not participate in sports activities due to retirement or busyness $(\mathrm{N}=40)$. Of the 118 patients who were able to re-engage in sports activities, 94 were the subjects of this study (figure 6). Table II shows the main sports.

\section{Patient demographics}

As regards to age, the subjects in the good group were 38.0 \pm 11.6 years old and those in the poor group were $44.0 \pm$ 11.5 years old (table III), and the difference was significant (table IV). A significant difference in the HRHI was found between the good group (95.9\%; range, 60.0-105.0) and the poor group (82.6\%; range, 60.9-100.0). The ATRA was 78.6 \pm 16.2 in the good group and $67.3 \pm 18.8$ in the poor group, showing a significant difference.

Table III. Patient demographic.

\begin{tabular}{|c|c|c|c|c|}
\hline & Good group $(N=68)$ & Poor group $(\mathrm{N}=26)$ & P value & Statics \\
\hline $\begin{array}{l}\text { Subjective recovery } \\
\text { degree scores(point) }\end{array}$ & $\begin{array}{l}86.9 \pm 6.4 \\
85.0(80.0-100)\end{array}$ & $\begin{array}{l}62.7 \pm 13.1 \\
70.0(22.0-80.0)\end{array}$ & - & - \\
\hline waiting period day) & $5.0(1.0-19.0)$ & 6.0.(0.0-20.0) & 0.882 & $\mathrm{U}$ \\
\hline Average Age (year) & $38.0 \pm 11.6$ & $44.0 \pm 11.5$ & $<0.025$ & $\mathrm{~T}$ \\
\hline ATRA $(\%)$ & $78.6 \pm 16.2$ & $67.3 \pm 18.8$ & $<0.005$ & $\mathrm{~T}$ \\
\hline HRHI (\%) & $95.9(60.0-105.0)$ & $82.6(60.9-100.0)$ & $<0.001$ & $\mathrm{U}$ \\
\hline The Pain rate $(\%)$ & 16.2 & 26.9 & 0.236 & $\chi^{2}$ \\
\hline The Anxiety rate (\%) & 58.8 & 61.5 & 0.810 & $\chi^{2}$ \\
\hline
\end{tabular}

Table II. Main sports events in the good group and poor group.

\begin{tabular}{lr}
\hline Good group & $\mathrm{N}$ \\
\hline Soccer, Futsal & 12 \\
\hline Badminton & 11 \\
\hline Basketball & 11 \\
\hline Tennis & 6 \\
\hline Volleyball & 4 \\
\hline Kendo & 3 \\
\hline Martial arts & 2 \\
\hline Baseball & 1 \\
\hline Other & 19 \\
\hline
\end{tabular}

\begin{tabular}{lc}
\hline Poor group & $\mathrm{N}$ \\
\hline Badminton & 5 \\
\hline Soccer, Futsal & 4 \\
\hline Basketball & 4 \\
\hline Tennis & 3 \\
\hline Baseball & 1 \\
\hline Other & 9 \\
\hline
\end{tabular}

\section{Movement starting time and achieved time}

Full dorsal flexion was achieved at 12.0 (range, 6.0-24.0) weeks in the good group and at 10.0 (range, 6.0-25.0) weeks in the poor group (table IV), showing a significant difference in surgical outcomes and start time of returning to sports. Continuous HR was achieved at 4.0 (range, 2.3-6.5) 
Table IV. Movement starting time and achieved time.

\begin{tabular}{lllll}
\hline & Good group $(\mathbf{N}=\mathbf{6 8})$ & Poor group $(\mathbf{N}=\mathbf{2 6})$ & P value & Statics \\
\hline Full Dorsal flexion ROM achieved (week) & $12.0(6.0-24.0)$ & $10.0(6.0-25.0)$ & $<0.036$ & $\mathrm{U}$ \\
\hline Jogging start (week) & $13.0(9.0-20.0)$ & $16.0(10.0-25.0)$ & 0.122 & $\mathrm{U}$ \\
\hline HRHI 50\% achieved (week) & $12.0(4.0-20.0)$ & $14.5(9.0-25.0)$ & 0.222 & $\mathrm{U}$ \\
\hline Continuous HR achieved (month) & $4.0(2.3-6.5)$ & $4.5(2.5-7.0)$ & $<0.000$ & $\mathrm{U}$ \\
\hline Jumpping Movement achieved (month) & $5.0(3.5-7.0)$ & $6.0(3.5-8.0)$ & $<0.001$ & $\mathrm{U}$ \\
\hline Return to sports achieved (month) & $5.5(4.0-8.0)$ & $6.5(4.5-8.0)$ & $<0.001$ & $\mathrm{U}$ \\
\hline & Median (MIN-MAX) & & & \\
\hline
\end{tabular}

months in the good group and at 4.5 (range, 2.5-7.0) months in the poor group, showing a significant difference. Jumping movement was achieved at 5.0 (range, 3.5-7.0) months in the good group and at 6.0 (range, 3.5-8.0) months in the poor group, showing a significant difference. Return to sports was achieved at 5.5 (range, 4.0-8.0) months in the good group and at 6.5 (range, 4.5-8.0) months in the poor group, and the difference was statistically significant. No significant difference was found in other items.

\section{Outcomes of interest}

Of the 94 subjects, 68 and 26 subjects belonged to the good and poor groups, respectively (table $\mathbf{V}$ ). The extracted factor was only HRHI (odds ratio, 1.104, 95\% confidence interval 1.051-1.160, discriminant intermediate rate, $73.4 \%$ ). The cutoff HRHI value was $89.5 \%$ (sensitivity, 0.794 ; 1 -specificity, 0.192 ; positive predictive value, $79.4 \%$; negative predictive value, $80.8 \%$; area under the curve (AUC), 78.6\%). Other outcomes that were examined were not extracted.

The cutoff ATRA value from the ROC curve based on this HRHI was $72.4 \%$ (sensitivity, 0.797; 1-specificity, 0.371; positive predictive value, $71.2 \%$; negative predictive value, 68.6\%; AUC, 74.6\%).

\section{DISCUSSION}

It is important to know whether the subjects that returned to sports were able to carry out sports activities to a satisfac- tory level and to clarify what kind of function was necessary. The biggest goal after surgery was the return to sports. The rate of return to sports after Achilles tendon repair in our hospital was $79.7 \%$, which is considered to be as good as the return rate of $80 \%$ reported by Zellers et al. (23).

In this study, only the HRHI was extracted as a necessary factor for sufficient sports activities; it was not extracted as an influencing factor like age BMI, pain, and anxiety. The results of this study clearly present that an HRHI of approximately $90 \%$ is an indicator of good function at 9 months after surgery. Furthermore, the ATRA required for the HRHI was approximately $70 \%$ on the unaffected side.

Single-leg HR is a method of evaluating the strength of the triceps surae muscle trough the Achilles tendon, and HRHI evaluates functional recovery based on the laterality of the unaffected side (24). Therefore, single-leg HR was evaluated as an index of functional recovery after Achilles tendon repair. We have previously reported that acquisition of a single-leg HR and continuous HR are necessary for sports movement acquisition and, as a result, return to sports $(4,5)$. We also reported that a continuous single-leg HR is defined as more than half the capacity of the unaffected side, and acquiring this movement and the return to sports show a correlation $(\mathrm{r}=0.433 \mathrm{P}<0.001)$ (5). However, it was necessary to clarify whether the maximum elevation of the single-leg HR should be the same as that of the unaffected side for sufficient functioning during sports activities. In addition, some studies have reported the relationship between the HRHI and ATRA, such as those by Zellers et al. (11), Silbernagel et al. (24), and Kangas et al. (25), Carmont

Table V. Multiple logistic regression analysis result (poor group and good group).

\begin{tabular}{ccccccc}
\hline B & Standard error & Wald & $\begin{array}{l}\text { Degree } \\
\text { of freedom }\end{array}$ & Significance & Odds rate & 95\%Confidence interval \\
\hline & & & & 1.104 & minimum & maximum \\
\hline HRHI 0.099 & 0.025 & 15.349 & 1 & 0.000 & 1.051 & 1.160 \\
\hline Poor
\end{tabular}

Poor goup: 0, good group: 1 ; model ${ }^{\chi_{2}}$ Test $\mathrm{p}<0.01$; Hosmer-Lemeshow Test $\mathrm{p}=0.080$; Discriminant intermediate rate: $73.4 \%$. 
MR et al. (26). However, it was unclear whether increased ATRA could lead to an increase in muscle strength.

In the rehabilitation course after Achilles tendon rupture repair, we actively prevent and remove adhesions around the Achilles tendon to "create an environment that does not inhibit the sliding of the Achilles tendon" (27). A study reported that exercise therapy from the early postoperative period had excellent mechanical effects on the ligaments and tendons and made adhesions less likely to occur $(28,29)$. The degree of adhesions around the Achilles tendon affects the patient's subjective satisfaction level (30). However, adhesions around the Achilles tendon are inevitable after Achilles tendon rupture repair. Subsequent soft tissue, fat pad, and Kager's fat pad hardening occur (31), and adhesions and loss of elasticity may be two factors that cause range of motion limitation and pain, which can interfere with tendon microcirculation and reduce tendon strength (32). The range of motion training in cases of adhesions may exert excessive stress on the tendon sutures and stretches the tendon.

Elongation of the Achilles tendon results from the weakness of the triceps surae muscle $(7,11,12)$, which is reported to affect HRHI and performance. Brorsson et al. (33) compared two groups with single-leg HR-deficient rates on the unaffected side of $\geq 30 \%$ and $<15 \%$ and reported that the group with $<15 \%$ had good clinical results. Carmont et al. (8), contrarily report that surgery needs to increase suture strength to eliminate the difference in ATRA. However, if the sutures are too strong, ATRA may be minimized, but range of motion is more likely to be restricted and more likely to cause pain. As a result, it lowers HRHI due to pain. Based on the results of this study, the flexion ATRA required to increase the HRHI to approximately $90 \%$ that enables sufficient sports activity is approximately $70 \%$. Carmont $e t$ al. (8) reported that 12 -month ATRS is $87 \%$, HRHI is $82 \%$, and ATRA is about $-5^{\circ}$ on the healthy side, concurring with the results of this study and are valid target values following Achilles tendon suture. To maintain this angle, good gliding of the Achilles tendon was ensured by preventing and removing adhesions above the tendon, paying attention to suturing to the plantar flexion angle during surgery. Based on the results of this study, it is important to aim for a dorsi-

\section{REFERENCES}

1. Domej-Arverud E, Anundsson P, Hardell E, et al. Ageing, deep vein thrombosis and male gender predict poor outcome after acute Achilles tendon rupture. Bone Joint J 2016;98:1635-41. flexion angle that does not differ between the left and right at 10-12 weeks following the surgery.

This study has some limitations. This study is not a quantitative assessment as it does not use a strength tester to assess strength. Therefore, the results here cannot be used to objectively assess the strength of the triceps surae. In addition, it is not possible to accurately evaluate the extension of the Achilles tendon because image evaluation by echo or MRI was not performed. Moreover, the presence and degree of adhesions and tendon gliding have not been accurately evaluated. In addition, the relationship with motor function is immature because no quantitative movement drill evaluation of steps and jumps was performed.

In this study, patients were classified into two groups by applying the Subjective Numerical Evaluation Scale (NRS). This method is an easy and effective way to quickly record the patient's subjective activities opinion to be used the evaluation. However, in many studies, subjective evaluation after Achilles tendon surgery is often reported using ATRS, so we will discuss it with other papers by clarifying the relationship between this NRS evaluation and ATRS evaluation in the future. I think the consistency of can be made clearer Improving the follow-up rate and extending the long-term follow-up period of one to two years are additional future study aims. It is also necessary to clarify the relationship between the characteristics of each sport and physical characteristics-such as muscle strength evaluation, posture evaluation, and bone morphology evaluation of other joints-in other future studies.

\section{CONCLUSIONS}

After Achilles tendon rupture repair, the HRHI required for good sports activity was approximately $90 \%$ of the unaffected side and the ATRA required for the same HRHI was > $70 \%$. In addition to the resting angle, improving the gliding of the tendon perioperatively is necessary to prevent elongation of the Achilles tendon. Rehabilitation after Achilles tendon repair is essential for functional recovery.

\section{CONFLICT OF INTERESTS}

The authors declare that they have no conflict of interests.

2. Olsson N, Petzold M, Brorsson A, Karlsson J, Eriksson BK, Silbernagel KG. Predictors of clinical outcome after acute Achilles tendon ruptures. Am J Sports Med 2014;42:1448-55 
3. Carmont MR, Zellers JA, Brorsson A, et al. Functional outcomes of Achilles tendon minimally invasive repair using 4- and 6- strand non-absorbable suture: A cohort comparison study. Orthop J Sports Med 2017;5:2325967117723347.

4. Uchiyama E, Nomura A, Takeda Y, Hiranuma K, Iwaso H. A modified operation for Achilles tendon ruptures. Am J Sports Med 2007;35:1739-43.

5. Imaya T, Uchiyama E, Fukai A, et al. Recovery of physical performance and foot function after surgical repair of Achilles tendon rupture: standardization of the evaluation method of the standing heel-rise test. Japanese J. Phys. Fit. Sports Med 2017;25:215-222. Article in Japanese.

6. Sanada T, Uchiyama E. Gravity equinus position to control the tendon length of reversed free tendon flap reconstruction for chronic Achilles tendon rupture. J Foot Ankle Surg 2017;56:37-41.

7. Silbernagel KG, Steele R, Manal K. Deficits in heel-rise height and Achilles tendon elongation occur in patients recovering from an Achilles tendon rupture. Am J Sports Med 2012;40:1564-71.

8. Carmont MR, Zellers JA, Brorsson A, Nilsson-Helander K, Karlsson J, Silbernagel KG. Age and tightness of repair are predictors of heel-rise height after Achilles tendon rupture. Orthop J Sports Med 2020;8:232596712090955.

9. Maquirriain J. Achilles tendon rupture: Avoiding tendon lengthening during surgical repair and rehabilitation. Yale J Biol Med 2011;84:289-90.

10. Molloy A, Wood EV. Complications of treatment of Achilles tendon ruptures. Foot Ankle Clin 2009;14:745-59.

11. Zellers JA, Carmont MR, Silbernagel KG. Achilles tendon resting angle relates to tendon length and function. Foot Ankle Int 2018;39:343-8.

12. Carmont MR, Silbernagel KG, Brorsson A, Olsson N, Maffulli $\mathrm{N}$, Karlsson J. The Achilles tendon resting angle as an indirect measure of Achilles tendon length following rupture, repair and rehabilitation. Asia Pac J Sports Med Arthrosc Rehabil Technol 2015;2:49-55.

13. Groetelaers RP, Janssen L, van der Velden J, et al. Functional treatment or cast immobilization after minimally invasive repair of an Achilles tendon rupture: prospective, randomized trial. Foot Ankle Int 2014;35:771-8.

14. Hsu AR, Jones CP, Cohen BE, Davis WH, Ellington JK, Anderson RB. Clinical outcomes and complications of percutaneous Achilles repair system versus open technique for acute Achilles tendon ruptures. Foot Ankle Int 2015;36:1279-86.

15. Liechti DJ, Moatshe G, Backus JD, Marchetti DC, Clanton TO. A percutaneous knotless technique for acute Achilles tendon ruptures. Arthrosc Tech 2018;7:e171-e178.

16. Padulo J, Oliva F, Frizziero A, Maffulli N. Muscle, Ligaments and Tendons Journal - Basic principles and recommendations in clinical and field Science Research: 2018 update. Muscles Ligaments Tendons J 2018;8(3):305-7.

17. Saxena A, Ewen B, Maffulli N. Rehabilitation of the operated achilles tendon: parameters for predicting return to activity. J Foot Ankle Surg 2011;50(1):37-40.

18. Amin NH, Old AB, Tabb LP, Garg R, Toossi N, Cerynik DL. Performance outcomes after repair of complete achilles tendon ruptures in national basketball association players. Am J Sports Med 2013 41:1864-8.
19. Maffulli N, Oliva F, Maffulli GD, Buono AD, Gougoulias N. Surgical management of chronic Achilles tendon ruptures using less invasive techniques. Foot Ankle Surg 2018;24(2):164-70.

20. Munegato D, Gridavilla G, Guerrasio S, et al. Mini open versus open repair techniques in Achilles tendon rupture: clinical and isokinetic evaluation. Muscle Ligaments Tendons J 2017;7 (3):554-61.

21. Chiu CH, Yeh WL, Tsai MC, Chang SS, Hsu KY, Chan YS. Endoscopy-assisted percutaneous repair of acute Achilles tendon tears. Foot Ankle Int 2013;34:1168-76.

22. Lacoste S, Féron JM, Cherrier B. Percutaneous Tenolig(®) repair under intra-operative ultrasonography guidance in acute Achilles tendon rupture.Orthop Traumatol Surg Res 2014;100:925-30.

23. Zellers JA, Carmont MR, Silbernagel KG. Return to play post-Achilles tendon rupture: A systematic review and meta-analysis of rate and measures of return to play. Br J Sports Med 2016;50:1325-32.

24. Silbernagel KG, Nilsson-Helander K, Thomeé E, Eriksson BI, Karlsson J. A new measurement of heel-rise endurance with the ability to detect functional deficits in patients with Achilles tendon rupture. Knee Surg Sports Traumatol Arthrosc 2010;18:258-64.

25. Kangas J, Pajala A, Ohtonen P, Juhana L. Achilles tendon elongation after rupture repair:

A randomized comparison of 2 postoperative regimens. Am J Sports Med 2007;35:59-64.

26. Carmont MR, Brorsson A, Karlsson J, Nilsson-Helander K. No difference in Achilles Tendon Resting Angle, Patient-reported outcome or Heel-rise height Index between Non- and Early-weightbearing the First Year after an Achilles Tendon Rupture. Muscle Ligaments Tendons J 2020;10(4):651-8.

27. Kannas S, Jeardeau TA, Bishop AT. Rehabilitation following zone II flexor tendon repairs. Tech Hand Up Extrem Surg 2015;19:2-10.

28. Woo SL, Inoue M, McGurk-Burleson E. Treatment of the medial collateral ligament injury. II: Structure and function of canine knees in response to differing treatment regimens. Am J Sports Med 1987;15:22-9.

29. Maffulli G, Del Buono A, Richards P, Oliva F, Maffulli N. Conservative, minimally invasive and open surgical repair for management of acute ruptures of the Achilles tendon: a clinical and functional retrospective study. Muscle Ligaments Tendons J 2017;7 (1):46-52.

30. Mortensen HM, Skov O, Jensen PE. Early motion of the ankle after operative treatment of a rupture of the Achilles tendon. A prospective, randomized clinical and radiographic study. J Bone Joint Surg Am 1999;81:983-90.

31. Wu YF, Tang JB. Apoptosis in adhesions and the adhesion-tendon gliding interface: relationship to adhesion-tendon gliding mechanics. J Hand Surg Am 2013;38:1071-8.

32. Chang YP, Shih KS, Chiang H, et al. Characteristics of intratendinous microcirculation shortly after an Achilles rupture and subsequent treatment outcomes. PM R 2017;9:32-9.

33. Brorsson A, Willy RW, Tranberg R, Silbernagel KG. Heel-rise height deficit 1 year after Achilles tendon rupture relates to changes in ankle biomechanics 6 years after injury. Am J Sports Med 2017;45:3060-8. 